PERSPECTIVE OPEN

\title{
Corrosion avoidance in lightweight materials for automotive applications
}

\author{
Ming Liu', Yang Guo', Jeff Wang ${ }^{1}$ and Mark Yergin ${ }^{2}$
}

Due to increasing vehicle greenhouse gas emission regulations across the globe, the automotive industry is facing pressure to improving fuel economy. The key to achieving this is reducing vehicle mass and developing alternative energy vehicles, thereby reducing environmental impact. Lightweighting has become one of the most important aspects to consider in the design and manufacture of modern vehicles, while electric vehicles require a different approach to design and build. All the aforementioned factors have a significant impact on materials selection and usage, and corrosion is a vital consideration. In this article, we discuss and summarize some of the challenges and demands of future fuel-efficient vehicles, from the perspective of corrosion avoidance

npj Materials Degradation (2018)2:24 ; doi:10.1038/s41529-018-0045-2

\section{CORROSION SOLUTION FOR AUTOMOTIVE LIGHTWEIGHTING MATERIALS SYSTEMS}

Presently, most automotive manufacturers are reducing vehicle structure mass, with several advanced materials being used (aside from traditional/conventional low carbon steel) including advanced high strength steels, ultra-high strength steels, aluminum (Al) alloys, magnesium (Mg) alloys, and composites. Materials selection depends upon where each material can be best optimized, in terms of performance and cost. Traditionally, motor vehicles have mainly consisted of iron and steel. The use of $\mathrm{Al}$ in the automotive sector has increased in recent decades, most OEM's (original equipment manufacturers) typically commencing with the utilization of $\mathrm{Al}$ hoods, one of the reasons being the comparative excellent corrosion resistance. However, with the ongoing pursuit of even lighter materials, which may not provide equally good corrosion resistance, a greater understanding of the corrosion behavior of emerging automotive materials is required.

\section{Corrosion and protection solutions for $\mathrm{Mg}$}

Magnesium is the lightest engineering metal for structural applications, having been utilized in vehicles for a long time (typical application includes instrument panel beam and steering wheel). However, the growth of $\mathrm{Mg}$ usage in the automotive sector was not as significant as many may have expected in the last two decades. In fact, since the high pressure die cast $\mathrm{Mg}$ instrument panel has been progressively replaced, the average usage of $\mathrm{Mg}$ alloys on a vehicle has declined since $2008 .^{1-3}$ One of the principal concerns is the poor corrosion resistance of $\mathrm{Mg}$ and Mg alloys. ${ }^{4}$

The poor corrosion resistance of $\mathrm{Mg}$ alloys is intrinsic, with $\mathrm{Mg}$ having the lowest (least noble) electrochemical potential of any metals used in automotive structures. ${ }^{5-9}$ Compared to $\mathrm{Al}$, which is also a reactive metal, $\mathrm{Mg}$ has a porous and unprotective surface oxide layer, which does not provide passivation from corrosion, unlike the passivation observed upon Al alloys. Ongoing efforts are aimed at the use of various alloying elements, with the pursuit of achieving more "stainless Mg." ${ }^{10,11}$ However, no significant progress has been made in the availability of corrosion-resistant commercial $\mathrm{Mg}$ alloys, with AZ91D (nominally Mg-9Al-1Zn $(-0.4 \mathrm{Mn}), \mathrm{wt} \%)$ and AM60 (nominally Mg-6Al-1Mn, wt\%) still the most popular Mg alloys for the automotive industry.

The use of a barrier coating is one solution in order to prevent $\mathrm{Mg}$ alloy corrosion; however, despite the effectiveness of such coatings, they also have the potential to create unfavorable anode/cathode area ratios at coating defect sites. Furthermore, previous experience has indicated that most current organic or epoxy-based coatings cannot permanently or fully prevent the penetration of aqueous electrolyte to the underlying $\mathrm{Mg}$ substrate. Once an aqueous electrolyte reaches any $\mathrm{Mg}$ substrate, the corrosion reaction can initiate and proceed (without the need for oxygen) and result in hydrogen generation. The generation of hydrogen will result in the formation of blisters beneath the coating and eventually compromise the corrosion protection system. As a result, organic or epoxy-based coatings cannot be directly applied on to an Mg substrate. ${ }^{12}$ Undoubtedly, in the lifetime of a vehicle, some abuse (intentional or accidental) or damage is expected during usage, especially for exterior applications, so there must be some tolerance for deep scratches or mild damage-as required. By comparison, the corrosion resistance of $\mathrm{Al}$ is superior to that of both steel and $\mathrm{Mg}$. In the case of steel, protective coatings that are sacrificial are possible, and there are numerous automotive steels that adopt the contemporary forms of classical $\mathrm{Zn}$ coatings. However, owing to the reactivity of $\mathrm{Mg}$ and its position in the galvanic series, it remains challenging (and commercially not yet realized) to develop a sacrificial coating for Mg substrates. It is worth noting, however, that laboratory scale attempts have been made to date ${ }^{13-15}$ with further work required.

The reactivity and aforementioned low electrochemical potential of $\mathrm{Mg}$ also makes $\mathrm{Mg}$ alloys very susceptible to galvanic corrosion, ${ }^{16}$ when in contact with essentially all other automotive alloys. This susceptibility to galvanic corrosion has been a key contributor greatly limiting the application of $\mathrm{Mg}$ in automotive

\footnotetext{
${ }^{1}$ China Science Lab, GM Global R\&D56, Jinwan Road, Pudong 201206 Shanghai, China and ${ }^{2}$ GM Corrosion Engineering and Laboratory, 3300 General Motors Road, Milford, MI 48380, USA

Correspondence: Ming Liu (ming.liu@gm.com)
}

Received: 17 January 2018 Revised: 25 May 2018 Accepted: 31 May 2018

Published online: 03 September 2018 

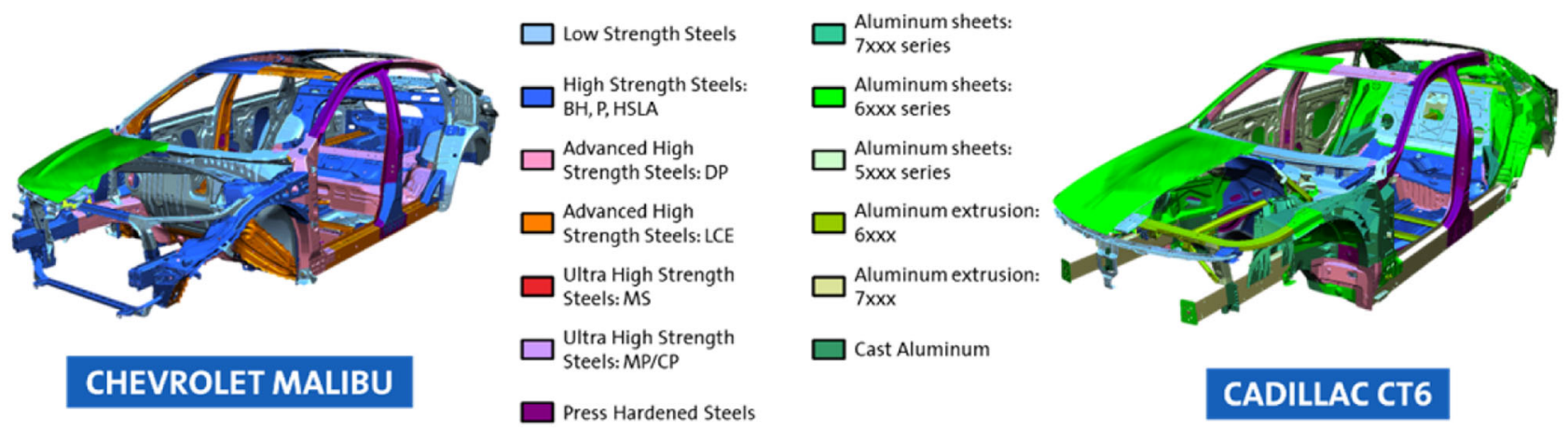

Fig. 1 Mixed materials BIW for Chevrolet Malibu and Cadillac CT6 (courtesy of General Motors)

industry. What also complicates the use of $\mathrm{Mg}$ alloys in automotive applications to date is that, in many cases, the design of the Mg component is usually transferred from the prior steel or Al designs, where galvanic interaction concerns are not present. In reality, a corrosion engineer is usually not involved in the early stages of design, which is typically more focused on finite element analysis optimization for structural requirements, and then flow simulation for the casting process. Such designs, however, may be later deemed inappropriate from failure to pass corrosion testing during the later stages of component validation; cause significant time and cost to modify the design and tooling. In some cases, such a delay is not acceptable for product launch, which can lead to reverting to the original steel or Al design. While electrical isolation can mitigate galvanic corrosion effectively, ${ }^{17,18}$ this engineering method, however, often brings additional cost and weight-making the Mg solution less competitive.

To address the above practical issues, the following applied areas should be considered:

- For current engineering applications, a systematic study regarding the compatibility of $\mathrm{Mg}$ and its alloys with other engineering materials is necessary. Developing the best practices or guidance for $\mathrm{Mg}$ component design to mitigate galvanic corrosion (which can be applied by vehicle designers).

- In the short term, developing a robust, self-healing, affordable, and environmentally friendly coating system for $\mathrm{Mg}$ alloys is of significance. Such a coating system should have scratch resistance and meet existing industry requirements, such as GMW/SAE/ISO-related standards. To make such a coating competitive, an ideal target cost should be below $1 \mathrm{USD} / \mathrm{m}^{2}$.

- In the longer term, developing a corrosion-resistant Mg alloy that has a corrosion rate $<0.1 \mathrm{~mm} /$ year (typically after 7 days immersion in $3.5 \mathrm{wt} \% \mathrm{NaCl}$ solution) or has corrosion performance equivalent to or better than competitor Al alloys (such as Silafont 36, A356, or even AA5xxx and AA6xxx alloys) in corrosion tests (such as the ASTM B117 neutral salt spray test or GMW 14872 cyclic salt spray test). This may be achieved by adding alloying element forms to promote corrosion resistance or promote the development of a dense passive film on the surface.

Galvanic corrosion between carbon fiber-reinforced polymer and metal

Carbon fiber-reinforced composites (CFRPs) and other fiberreinforced composites are attractive to engineers and manufacturers, because they possess a high specific strength, and are promising lightweight materials for vehicle applications. Although the polymeric resins may have some susceptibility to degradation, generally however, fiber-reinforced composites are considered stable and corrosion resistant. However, when reinforced with carbon fibers, there may be subsequent corrosion issues that arise, when joining carbon fiber composites with metals. Carbon fibers in CFRPs are electrically conductive, and electrochemically very noble. Therefore, when a metal or alloy is inappropriately joined with CFRP (such that there is an electrical connection), the metal is susceptible to suffer galvanic corrosion. When coupled with a fastener, bolt, or nut, the situation worsens, because a large surface area of CFRP is coupled to small metallic parts. In these circumstances, the rate of galvanic corrosion may be accelerated due the high cathode to anode surface area ratio $\left(A_{\mathrm{c}} / A_{\mathrm{a}}\right)$.

The galvanic corrosion of metals coupled to carbon composite materials is actually not entirely new, having been reported since the 1970s. ${ }^{19}$ The issue has also been topical for decades in the context of the aerospace industry, ${ }^{20}$ which has now adopted CFRPs in contemporary aircraft. In the context of automotive alloys, there was a recent study coupling CFRP to coated steel ${ }^{21}$ revealing the galvanic corrosion behavior of a CFRP/steel couple is critically dependent on the CFRP's surface polymer layer conditions. The ongoing demand for the use of CFRP in automotive applications requires further systematic study of the galvanic corrosion between carbon fiber composites and automotive engineering materials, including a range of steels (with a range of surface treatments) and numerous $\mathrm{Al}$ alloys. Especially important is the influence of different materials combinations, geometries, and joining methods on the subsequent corrosion intensity. It remains to be realized that the desired outcome of mitigating galvanic corrosion be achieved by selecting the appropriate materials and appropriate design of the joining method.

Galvanic corrosion for the mixed materials strategy in body-inwhite

The so-called body-in-white (BIW) refers to the stage in automotive design/manufacturing in which the body's components have been joined together. Among the various strategies to remove weight from vehicles, one is the "mixed materials strategy" of using the right material in the right place in the right amount. It is noted that mixed-material vehicles are by no means something new. A whole vehicle is, in general, made from mixed materials at present, including $\mathrm{Al}$ engine blocks and suspension parts, steel bodies, plastic trim, and Mg instrument panel support beams. However, such parts are typically attached to a predominantly steel body (i.e., a steel BIW) in final assembly. To achieve an even lighter vehicle with higher stiffness, a more complicated "hybrid" of different materials is required for body structure. Taking the Cadillac CT6, for example, it is General Motors' first complete vehicle with a body made from mixed materials-incorporating several grades of steel sheet, Al sheet, castings, and extrusions as show in Fig. 1. Similar trend can now be found in other vehicles, such as the present Chevrolet Malibu. To meet structural integrity requirements, conventional and newly 
developed joining techniques have been applied, including the extensive use of adhesives.

Galvanic corrosion, different thermal extension, and other effects of bringing two or more dissimilar materials and alloys closely together must be addressed. For corrosion, that means combining various materials with different electrode potentials, which can result in the possibility of galvanic corrosion. Traditionally, galvanic corrosion was mainly evaluated by experimental methods. In terms of understanding (or estimating) galvanic corrosion a priori, the application of numerical methods such as the boundary element method to galvanic corrosion has been reported by numerous authors ${ }^{22-27}$ and commercially available software like $\mathrm{BEASY}^{\circledR}$ has demonstrated the potential to predict galvanic current distribution in marine applications. It is however being noted that most of these attempts at modeling galvanic corrosion have been studies of the system fully immersed in electrolyte. However, in the case of automotive applications, the environment of actual usage is one in which materials are under a thin film electrolyte, with large variations in wetness and ambient humidity. In such cases, corrosion behavior (and galvanic corrosion behavior) will be complex due to the electrochemical system and the conductivity path constantly evolving/differing. Recently, BEASY ${ }^{\circledR}$ developed a thin film model to simulate the galvanic corrosion under thin film electrolyte, with a logical further pursuit being the wider spread experimental validation of such models. An initial study has been promising, indicating the prospect of predicting the salt spray test results on the component level. ${ }^{28}$ With further development, such combined modeling-experimental approaches may be useful in order to simulate the total current and potential distribution of a whole mixed materials vehicle under corrosion conditions, helping to guide in design.

Lab-to-field correlation and corrosion standard for new materials The automotive field has always remained dynamic, and although only some emerging materials of interest have been mentioned above, it is undoubtable that numerous new materials (or new variants of existing materials, such as new alloy grades, or materials with advanced surface treatments, etc.) will soon enter the vehicle manufacturing process. This inevitability brings with it a lot of challenges to corrosion validation. Present vehicles usually have corrosion requirements of 10 to 15 years and OEMs often provide approximately 3 to 6 years of warranty to the customer. Vehicle corrosion engineers and numerous OEMs have accumulated decades of historical data to develop a comprehensive corrosion avoidance and validation methodology. Therefore, OEMs and their suppliers have traditionally had an accurate (and relatively quick) assessment of the durability of automotive materials and components, using reasonable resources and time, during the typical 3- to 4-year-long full vehicle development cycle. Such an approach has proven to be effective to date, since products and parts which can pass these validation tests have historically held up as durable in actual market conditions. However, as may be guessed, most validation methods used to date are based on test data based on ferrous materials - with the majority of mass market vehicles built with low carbon steels for a long time. As highlighted through this commentary, the demand for new automotive materials (driven by the combination of efficiency and regulations) means that the present assessments, methodologies, and standards may not accurately correlate to future durability in actual service environments. Such a circumstance may lead to either under or over engineering. Therefore, a systematic study of the correlation between laboratory test results (which are necessarily accelerated in nature) and actual usage conditions for new materials becomes very important in order to permit the implementation of new materials effectively and efficiently.

\section{CORROSION FOR BATTERY ELECTRIC VEHICLE}

The arrival of alternative energy (non-gasoline) vehicles is inspiring a new era of innovation in the automotive industry, across several OEMs. Furthermore, as can be seen in the case of alternative energy vehicles, there are significant changes in the way such vehicles are designed and built. For example, this is especially true in the case of the battery electric vehicle, where the elimination of the internal combustion engine and transmission offers greater design freedom to engineers. Such design changes impact the materials usage and the attendant corrosion conditions. For example, Tesla have integrated the battery packs and electric motor on the chassis of their Model $S$, with no propulsion components located under the hood. To increase the amount of available power or to improve efficiency, a direct motor-to-wheel configuration could be applied in other cases, or even, wheel hub motors. In any such case, electric motors are placed at a position much closer to the wheel, where the working conditions (and environment) are much more severe than the under hood; this includes exposure to dust and dirt, stone chipping, and even salt water splashing. In such locations of the vehicle, a robust corrosion protection strategy must be developed and implemented.

In contrast, and historically, conventional internal combustion engine and transmission systems are more like a closed system. While corrosion may impact supporting systems (i.e., coolant system, cables, etc.), corrosion may not cause immediate functional loss for a vehicle. However, for electric vehicles, corrosion in specific areas such as connector blocks and terminals, can create a short circuit for electrical current and lead to arc ignition. All aspects are presently key issues of consideration (presently and in the near and ongoing future) and in need of systematic study and validation.

\section{CORROSION PROTECTION AND AVOIDANCE INSPIRED BY NEW TECHNOLOGIES}

Nowadays, it can be considered that vehicles are more than just a machine for transportation. Vehicles are now incorporating a significant number of functions, becoming both smart and intelligent. Tire pressure monitoring and other intelligent diagnosis systems have become standard equipment for many vehicles on the market, and it can therefore be expected that a corrosion monitoring system may be achieved in future. For example, appropriate sensors (noting that it was a decrease in the cost and increase in reliability of sensors that have allowed the rapid development of driverless vehicles), capable of real-time monitoring of the corrosion rates at critical locations, could potentially permit with proactive warnings before system failure. Such a system may be integrated into other vehicle health diagnosis modules to form a comprehensive vehicle monitoring system.

Finally, the recent development in machine learning and artificial intelligence have illuminated a new space for corrosion avoidance, from generating corrosion protection solutions, to monitoring corrosion data during validation and service. Just as digitization and then automation significantly improved the efficiency of corrosion measurement in the past, machine learning and artificial intelligence may provide new solutions and expert systems to collect field corrosion data and conduct big data analysis to generate a more accurate lab-to-field correlation. This is a topic that is not elaborated here, but a topic that is critical and relevant to the broader field of corrosion, in both materials design and anti-corrosion design, outside the scope of an existing engineers individual experience. 


\section{ACKNOWLEDGEMENTS}

We thank Dr. Mark Verbrugge and Dr. Anil Sachdev from General Motors Global R\&D for providing valuable discussion and suggestions.

\section{AUTHOR CONTRIBUTIONS}

M.L. drafted the manuscript and contributed to the sections "Corrosion and protection solutions for magnesium" and "Corrosion for battery electric vehicle." Y. G. contributed to the sections "Galvanic corrosion between carbon fiber-reinforced polymer (CFRP) and metal" and "Galvanic corrosion for the mixed materials strategy in body-in-white." J.W. contributed to the section "Corrosion protection and avoidance inspired by new technologies." M.Y. contributed to section "Lab-to-field correlation and corrosion standard for new materials" and provided his engineering prospective to the other sections in the manuscript.

\section{ADDITIONAL INFORMATION}

Competing interests: The authors declare no competing interests.

Publisher's note: Springer Nature remains neutral with regard to jurisdictional claims in published maps and institutional affiliations.

\section{REFERENCES}

1. Luo, A. Magnesium casting technology for structural applications. J. Magnes. Alloys 1, 2-22 (2013).

2. Joost, W. J. \& Krajewski, P. E. Towards magnesium alloys for high-volume automotive applications. Scr. Mater. 128, 107-112 (2017).

3. Wang, X., Xu, D., Wu, R., Chen, X. \& Peng, Q. et al. What is going on in magnesium alloys. J. Mater. Sci. Technol. 34, 245-247 (2018).

4. Brady, M. P., Joost, W. J. \& Warren, C. D. Insights from a recent meeting: current status and future directions in magnesium corrosion research. Corrosion 73, 452-462 (2017).

5. Song, G. \& Atrens, A. Corrosion mechanisms of magnesium alloys. Adv. Eng. Mater. 1, 11-33 (1999).

6. Song, G. \& Atrens, A. Understanding magnesium corrosion. Adv. Eng. Mater. 5, 837-858 (2003).

7. Song, G. Recent progress in corrosion and protection of magnesium alloys. Adv. Eng. Mater. 7, 563-586 (2005).

8. Song, G. \& Atrens, A. Recent insights into the mechanism of magnesium corrosion and research suggestions. Adv. Eng. Mater. 9, 177-183 (2007).

9. Atrens, A., Song, G.-L., Liu, M., Shi, Z. \& Cao, F. et al. Review of recent developments in the field of magnesium corrosion. Adv. Eng. Mater. 17, 400-453 (2015).

10. Birbills, N., Williams, G., Gusieva, K., Samaniego, A. \& Gibson, M. et al. Poisoning the corrosion of magnesium. Electrochem. Commun. 34, 295-298 (2013).

11. Liu, R., Hurley, M., Kvryan, A., Williams, G., Scully, J. et al. Controlling the corrosion and cathodic activation of magnesium via microalloying additions of Ge. Sci. Rep. 6, 28747 (2016).

12. Wang, C., Jiang, B., Liu, M. \& Ge, Y. Corrosion characterization of micro-arc oxidization composite electrophoretic coating on AZ31B magnesium alloy. J. Alloy. Compd. 621, 53-61 (2015).

13. Liu, M. \& Gao, L. Method of making corrosion resistant and glossy appearance coating for light metal workpiece. US patent 9,797,036 (2017).

14. Xu, W., Birbilis, N., Sha, G., Wang, Y., Daniels, J. E. et al. A high-specific-strength and corrosion-resistant magnesium alloy. Nat. Mater. 14, 1229-1235 (2015).
15. Liu, R., Thomas, S., Scully, J., Williams, G. \& Birbilis, N. An experimental survey of the cathodic activation of metals including $\mathrm{Mg}, \mathrm{Sc}, \mathrm{Gd}, \mathrm{La}, \mathrm{Al}, \mathrm{Sn}, \mathrm{Pb}$, and $\mathrm{Ge}$ in dilute chloride solutions of varying pH. Corrosion 73, 494-505 (2017).

16. Cain, T., Melia, M., Fitz-Gerald, J. \& Scully, J. Evaluation of the potential range for sacrificial $\mathrm{Mg}$ anodes for the cathodic protection of Mg alloy AZ31B-H24. Corrosion 73, 544-562 (2017).

17. Song, G., Luo, A. A. \& Gayden, X. Q. Methods of reducing corrosion between magnesium and another metal. US patent 8,231,936 (2012).

18. Luo, A. A., Verbrugge, M. W. \& Sachdev, A. K. Galvanic corrosion protection for magnesium components using cast-in-place isolators. US patent 7,845,388 (2010).

19. Brown, A. \& Coomber, D. E. Behaviour of Couples of aluminium and plastics reinforced with carbon fibre in aqueous salt solution. Br. Corros. J. 7, 232-235 (1972).

20. Palani, S., Hack, T., Deconinck, J. \& Lohner, H. Validation of predictive model for galvanic corrosion under thin electrolyte layers: an application to aluminium 2024-CFRP material combination. Corros. Sci. 78, 89-100 (2014).

21. Zhang, C., Zheng, D.-J. \& Song, G.-L. Galvanic effect between galvanized steel and carbon fiber reinforced polymers. Acta Metall. Sin. 30, 342-35 (2017).

22. Shi, Z., Jia, J. \& Atrens, A. Galvanostatic anodic polarization curves and galvanic corrosion of $\mathrm{AZ31B}$ in $0.01 \mathrm{M} \mathrm{Na}_{2} \mathrm{SO}_{4}$ saturated with $\mathrm{Mg}(\mathrm{OH})_{2}$. Adv. Eng. Mater. 14, 324-334 (2012)

23. Jia, J. X., Song, G. \& Atrens, A. Experimental measurement and computer simulation of galvanic corrosion of magnesium coupled to steel. Adv. Eng. Mater. 9, 65-74 (2007).

24. Jia, J. X., Song, G. \& Atrens, A. Influence of geometry on galvanic corrosion of AZ91D coupled to steel. Corros. Sci. 48, 2133-2153 (2006).

25. Jia, J. X., Song, G. \& Atrens, A. Boundary element method predictions of the influence of the electrolyte on the galvanic corrosion of AZ91D coupled to steel. Mater. Corros. 56, 259-270 (2005).

26. Jia, J. X., Atrens, A., Song, G. \& Muster, T. Simulation of galvanic corrosion of magnesium coupled to a steel fastener in $\mathrm{NaCl}$ solution. Mater. Corros. 56, 468-474 (2005).

27. Jia, J. X., Song, G., Atrens, A. \& St John, D. Evaluation of the BEASYprogram using linear and piecewise linear approaches for the boundary conditions. Mater. Corros. 55, 845-852 (2004).

28. Chen, Y., Liu, M., Zeng, X. \& Ding, W. Investigation of effect of geometry design on the galvanic corrosion of Mg component. Mater. Corros. 66, 949-962 (2015).

Open Access This article is licensed under a Creative Commons Attribution 4.0 International License, which permits use, sharing, adaptation, distribution and reproduction in any medium or format, as long as you give appropriate credit to the original author(s) and the source, provide a link to the Creative Commons license, and indicate if changes were made. The images or other third party material in this article are included in the article's Creative Commons license, unless indicated otherwise in a credit line to the material. If material is not included in the article's Creative Commons license and your intended use is not permitted by statutory regulation or exceeds the permitted use, you will need to obtain permission directly from the copyright holder. To view a copy of this license, visit http://creativecommons. org/licenses/by/4.0/.

(c) The Author(s) 2018 